\title{
Tracing of traffic-related pollution using magnetic properties of topsoils in Daejeon, Korea
}

\author{
Seungwoo Lee ${ }^{1}$ Seoyeon $\mathrm{Kim}^{1} \cdot$ Hyeji Kim ${ }^{1}$. Youlee Seo ${ }^{1}$ Yeoncheol Ha ${ }^{1} \cdot \mathrm{Hanul} \mathrm{Kim}^{2} \cdot \mathrm{Raegyung} \mathrm{Ha}^{2}$. \\ Yongjae $\mathrm{Yu}^{1,2}$ (1)
}

Received: 9 April 2020 / Accepted: 21 September 2020 / Published online: 16 October 2020

(c) The Author(s) 2020

\begin{abstract}
The present study was designed to explore the possibility of roadside pollution screening using magnetic properties of topsoil samples in Daejeon, South Korea. Low-field magnetic susceptibility, frequency dependence of magnetic susceptibility, susceptibility of anhysteretic remanent magnetization, isothermal remanent magnetization (IRM) acquisition and demagnetization, back-field IRM treatment, and thermal demagnetization of composite IRM were determined for roadside topsoil samples. Magnetic susceptibility measured on 238 samples from the upper $5 \mathrm{~cm}$ of the topsoils ranged from 8.6 to $82.5 \times 10^{-5} \mathrm{SI}$ with a mean of $28.3 \pm 10.8 \times 10^{-5} \mathrm{SI}$. The proximal zone, $55 \mathrm{~m}$ wide area situated on either side of the main street, exhibited an enhancement of magnetic susceptibility. In areas distant from the main street, low magnetic susceptibility $\left(<50 \times 10^{-5} \mathrm{SI}\right)$ was observed. The topsoil samples exhibited significant susceptibility contrasts, suggesting that two dimensional magnetic mapping was effective in identifying traffic-related pollution. A few magnetic hotspots with intensities of magnetic susceptibility near or over $50 \times 10^{-5} \mathrm{SI}$ might reflect the difference in topographic elevation and surface morphology. Among various IRM-related parameters, remanence of coercivity was most significant statistically. In most samples, IRM component analysis provided dual coercivity components. Thermal demagnetization of composite IRM and morphological observation of magnetic separates suggest angular magnetite produced by vehicle non-exhaust emissions spherical magnetite derived from exhaust emission to be the dominant contributors to the magnetic signal. It is likely that lower- and higher-coercivity components represent the presence of coarse-grained angular magnetite and fine-grained spherical magnetite, respectively.
\end{abstract}

Keyword Roadside pollution $\cdot$ Environmental magnetism $\cdot$ Magnetic susceptibility $\cdot$ Magnetic coercivity $\cdot$ Magnetite

\section{Introduction}

Soil contamination or soil pollution poses a serious global threat to our environment. Increased concentration of soil pollutants should be of concern worldwide because of their toxicological impacts on ecosystems. In particular, heavy metals can cause severe adverse effects on any non-targeted

Electronic supplementary material The online version of this article (https://doi.org/10.1007/s12665-020-09223-9) contains supplementary material, which is available to authorized users.

Yongjae $\mathrm{Yu}$

yongjaeyu@cnu.ac.kr

1 Department of Geological Sciences, Chungnam National University, Daejeon 34134, Korea

2 Department of Astronomy, Space Science and Geology, Chungnam National University, Daejeon 34134, Korea organism. It is generally considered that heavy metals accumulated in soils are derived from natural lithogenic or artificial anthropogenic sources (e.g., Karimi et al. 2017). In the absence of heavy industry, roadside dust is undoubtedly the most common sources of environmental pollution in urban areas (e.g., Bućko et al. 2011). Recently, the applicability of magnetic monitoring has increasingly been applied for the evaluation of anthropogenic pollution (e.g., Bućko et al. 2010).

Geochemical investigation provides the highest resolution in environmental studies in terms of quantitative evaluation of the degree of pollution as well as qualitative assessment of the pollution sources (e.g., Jordanova et al. 2013). However, geochemical investigation requires a great deal of chemical analyses, which are time-consuming, expensive, and destructive. In contrast, magnetic methods are rapid, cost effective, and non-destructive (e.g., Evans and Heller 2003). In practice, magnetic techniques provide a descent basis for 
a comprehensive geochemical investigation. Among various rock magnetic approaches, magnetic susceptibility is the most widely used tool to map and monitor the heavy metal pollution of soils (e.g., Hanesch et al. 2007; Yang et al. 2007, 2009; Blaha et al. 2008; Karimi et al. 2011, 2017; Dankoub et al. 2012; Ayoubi et al. 2019a, b; Ayoubi and Adman 2019; Ayoubi and Karimi 2019). Magnetic susceptibility reflects the amount of paramagnetic and ferromagnetic minerals in rocks and soils (e.g., Evans and Heller 2003).

In general, magnetic minerals present in soils have three distinctively different origins. First, unpolluted soils contain lithogenic magnetic minerals that were the product of weathering and transportation of parent rocks. Second, pedogenic process under aerobic conditions is responsible for the enhancement of magnetic susceptibility, by increasing the concentration of nano-sized magnetite and/or maghemite (e.g., Torrent et al. 2010; Liu et al. 2012; Ayoubi and Karami 2019). Third, polluted soils commonly contain significant amount of anthropogenic magnetic minerals. Presence of highly magnetic particles in polluted soils originates from anthropogenic contribution. Urban airborne particulates are enriched in heavy metals, acting as carriers of potentially hazardous heavy metals (e.g., Boyko et al. 2004). Magnetic properties have been used as a proxy for the heavy metal concentrations in soils (e.g., Hanesch and Scholger 2002; Jelenska et al. 2004; Schmidt et al. 2005; Dong et al. 2014; Grison et al. 2015; Ayoubi and Karimi 2019). Such a linkage came from the fact a combustion process is responsible for the enhancement of magnetic particulates and heavy metals in soils (e.g., Tolonen and Oldfield 1986). Therefore, soil magnetometry is useful as a first-order constraint on the degree of heavy metal pollution (e.g., Bućko et al. 2010; Ayoubi et al. 2019a, b).

In industrial regions, fine-grained magnetic particulate matters are produced by combustion of fossil fuels and other high temperature technogenic processes (e.g., Hanesch et al. 2003; Spiteri et al. 2005; Jordanova et al. 2006; Yan et al. 2011; Zhang et al. 2011; Zhu et al. 2013). On the other hand, the most important source of heavy metal pollutants in urban environments is roadside dust emission (e.g., Muxworthy et al. 2001; Gautam et al. 2004; Lu and Bai 2006; Kim et al. 2007; Lu et al. 2007; Werkenthin et al. 2014; Ojha et al. 2016). For instance, the primary constituent of automobile exhaust was found to be associated with magnetic particles. In addition, exterior rusting, internal exhaustion, and ablation of breaks also produce fine-grained magnetic particulate matters (e.g., Petrovský et al. 2000; Wawer et al. 2015; Ma et al. 2016). Thus, rock magnetic proxies have been applied to traffic-related roadside dusts (e.g., Prajapati et al. 2006; El-Hasan 2008; Maher et al. 2008; Lu et al. 2011; Nikolaeva et al. 2017; Pierwola et al. 2020). However, the correlation between pollutants and magnetic proxy was far from being a simple linear relation (e.g., Chaparro et al. 2004). As a result, it was necessary to generate magnetic mapping at a regional scale to assess the spatial distribution of pollutants for each independent investigation (e.g., Ayoubi and Adman 2019).

A regional scale magnetic investigation on roadside dust is rare in Korea (Kim et al. 2007). In this study, we tested magnetic measurements as a proxy to monitor the degree of roadside pollution. The main objective of this work was to identify detailed characteristics of the magnetic materials derived from circulation of traffic-derived roadside soils in Daejeon, South Korea. To unravel magnetic signal on the roadside dusts, low-field magnetic susceptibility, frequency dependence of magnetic susceptibility, susceptibility of anhysteretic remanent magnetization, isothermal remanent magnetization (IRM) acquisition and demagnetization, backfield IRM treatment, and thermal demagnetization of composite IRM will be carried out. In particular, we focused on the mutual relation between various high-field IRM-related properties.

\section{Methods and materials}

\section{Description of the study area and sampling}

South Korea is located in a transition zone between the humid subtropical zone and the humid continental climate zone. The monsoon-influenced climate is dominant over the summer and brings about $80 \%$ of the annual rainfalls. Daejeon is South Korea's fifth-largest metropolis with a population over 1.5 million (Fig. 1). In 2019, annual precipitation from rainfalls (and snowfalls) in Daejeon was $1458.6 \mathrm{~mm}$. According to climate data from 1981 to 2010 , monthly mean temperatures of Daejeon ranged from $-1.0^{\circ} \mathrm{C}$ in January to $25.6{ }^{\circ} \mathrm{C}$ in August. The mean elevation of Daejeon is $70 \mathrm{~m}$ a.s.l. A Jurassic two mica granite constitutes the basement of Daejeon area (Hwang and Moon 2018).

The meteorological parameters on the sampling date (June 28, 2019) were available from the Korea Meteorological Administration (https://www.weather.go.kr/). In detail, temperature ranged between 22.1 and $29.9^{\circ} \mathrm{C}$, while humidity was $76.3 \%$. The prevailing wind directions on June 28 , 2019 were SE and SSE, with low wind speeds of $1.5 \mathrm{~m} / \mathrm{s}$.

The Hanbat-daero is a major twelve-way street (Fig. 1), with the daily traffic volume over 100,000 vehicles on weekdays. It is not awkward to witness a heavy traffic queue during rush hours. The stream bridge (Yuseong-daegyo) is a street-stream crossroad, which is about $500 \mathrm{~m}$ away from the highway entrance. The deck height of the stream bridge is about $5 \mathrm{~m}$. At ground level of the bridge, there is a grassland, where we expect to check spatial variation of traffic-related pollution (Fig. 1). We set the base station (star symbol in Fig. 1) near to the main street $\left(36^{\circ} 21^{\prime} 32.19^{\prime \prime} \mathrm{N}\right.$, 


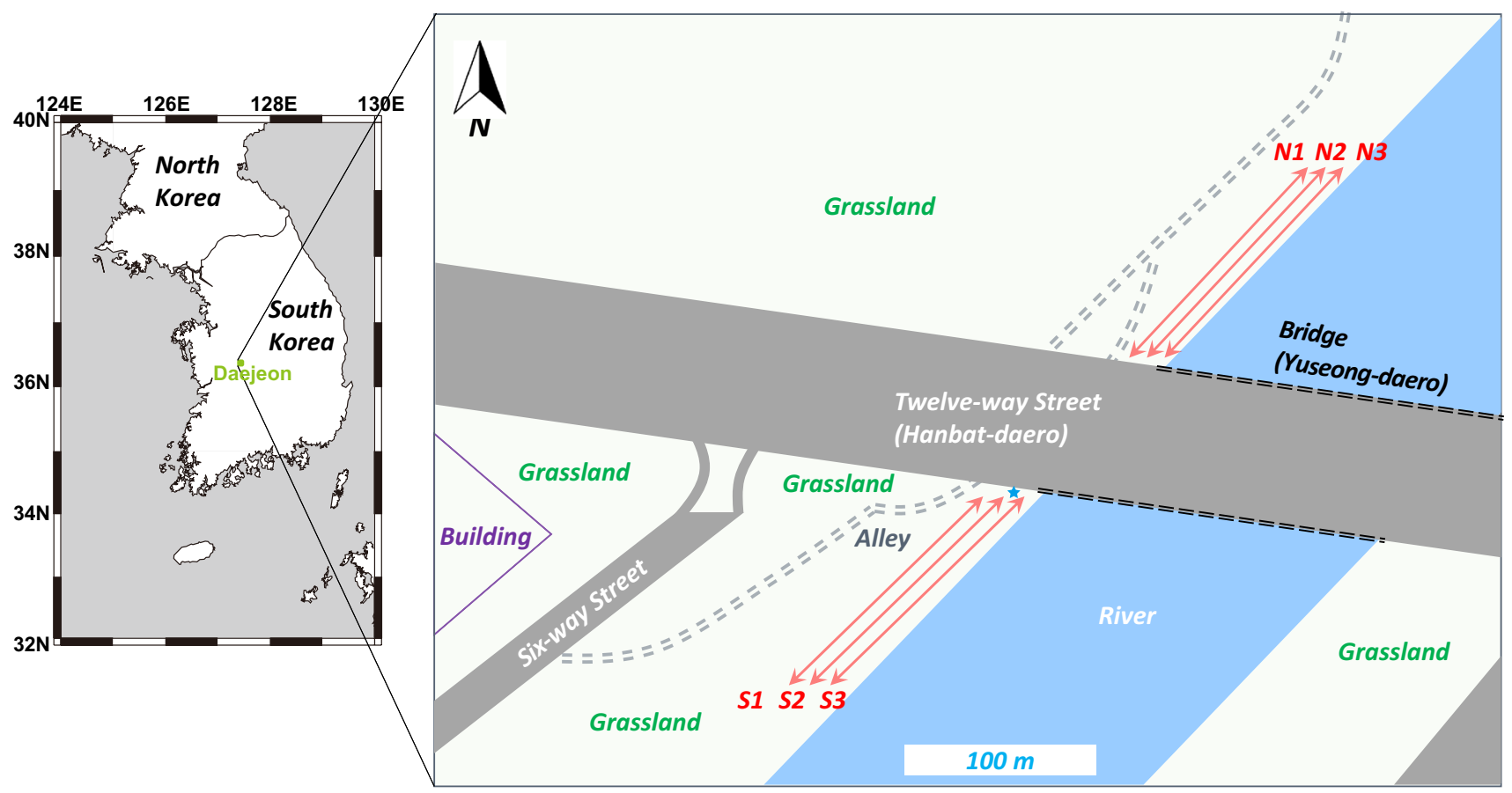

Fig. 1 In situ magnetic susceptibility traverses across urban street in Daejeon, South Korea measured on June 28, 2019. Magnetic susceptibilities were measured from a total of six profiles (N1, N2, N3, S1, $\mathrm{S} 2$, and S3). Each profile was $100 \mathrm{~m}$ long, set to be nearly perpendicular to the twelve-way street along the river. The inset was generated

$\left.127^{\circ} 21^{\prime} 27.49^{\prime \prime} \mathrm{E}\right)$. It is likely that vehicles are the only significant source of pollution in the grassland, because there is no nearby agricultural or industrial facilities (Fig. 1).

Magnetic susceptibilities were measured from a total of six profiles, three towards the south and three towards the north (Fig. 1). Each profile was $100 \mathrm{~m}$ long along the river, set to be nearly perpendicular to the twelve-way street (Fig. 1). Three profiles towards the south were separated by $5 \mathrm{~m}$ with one another, labeled as S1, S2, and S3. Similarly, three profiles towards the north were labeled as N1, N2, and N3. The net investigation area covered about $2000 \mathrm{~m}^{2}$ (200 $\mathrm{m}$ long and $10 \mathrm{~m}$ wide).

Magnetic susceptibilities were measured using a portable magnetic susceptibility meter ZH-instruments SM30 with a sensitivity of $10^{-7}$ SI. A total of 238 readings were taken (40 from S1, 31 from S2, 32 from S3, 40 from N1, 54 from N2, 41 from N3). Each data point was double or triple checked to ensure the reproducibility of signal. A total of 76 representative sites were selected (13 from $\mathrm{S} 1,10$ from $\mathrm{S} 2$, 10 from $\mathrm{S} 3,13$ from N1, 18 from N2, 12 from N3), where we collected samples from the upper $5 \mathrm{~cm}$ of the topsoils. These 76 sites were picked on the basis of magnetic susceptibility measurements including sites from the highest, from the "Generic Mapping Tools (GMT)" version 6.0.0 (released on November 1, 2019) distributed from the School of Ocean and Earth Science and Technology, University of Hawaii at Manoa (https://gmt. soest.hawaii.edu/). We set the base station (star symbol) near to the main street $\left(36^{\circ} 21^{\prime} 32.19^{\prime \prime} \mathrm{N}, 127^{\circ} 21^{\prime} 27.49^{\prime \prime} \mathrm{E}\right)$

lowest, and median (or mean if necessary) susceptibilities. The topsoils were un-stratified with loose, brown fine- to medium grains sand with occasional fine gravels. Whenever encountered, we discarded gravels. Samples were collected using a stainless steel trowel, and stored in a non-magnetic one-inch cube. Collected soil samples were placed in a sealed polyethylene bags and transported to the laboratory for further measurements. For these plastic cubes, magnetic susceptibilities were measured in the lab using a Bartington MS2 susceptibility bridge.

Presence of void induces grain motions in a plastic cube, resulting in inconsistent magnetic behavior. To prevent possible grain motions during magnetic measurements on spinning magnetometers, non-magnetic paraffin was used. It is well-known that non-magnetic solid paraffin has a melting point of $\approx 40{ }^{\circ} \mathrm{C}$. We injected liquid paraffin into empty spaces of plastic cubes and dried overnight. The remanent magnetization of a one-inch plastic cube with full paraffin had remanent magnetization 3000 fold lower than the weakest soil samples. Hence, the influence of paraffin injection was magnetically insignificant in the present study. Samples were weighed, and then stored in a refrigerator to minimize the effect of drying or moisturizing. 


\section{Laboratory analyses}

Magnetic susceptibilities $(\chi)$ were measured at low $\left(0.46 \mathrm{kHz} ; \chi_{\mathrm{lf}}\right)$ and high frequencies $\left(4.6 \mathrm{kHz}, \chi_{\mathrm{hf}}\right)$ using a Bartington MS2 dual frequency sensor. The frequency dependence $\left(\chi_{\mathrm{fd}}\right)$ was calculated as $\chi_{\mathrm{fd}}$ $(\%)=\left[\left(\chi_{\mathrm{lf}}-\chi_{\mathrm{hf}}\right) / \chi_{\mathrm{lf}}\right] \times 100$ to address the relative contribution of the superparamagnetic (SP) particles in the total magnetic fraction of the soils (Dearing et al. 1996).

Anhysteretic remanent magnetization (ARM) is produced when a steady external field is superimposed on a decaying alternating-field (AF). The susceptibility of ARM was determined as $\chi_{\mathrm{ARM}}=\mathrm{ARM} / B_{\mathrm{ARM}}$ for a field $B_{\mathrm{ARM}}$ of $0.05 \mathrm{mT}$ or $500 / 4 \pi=39.8 \mathrm{~A} / \mathrm{m}$ (Table 1 ).

To eliminate the influence of initial state dependence of remanent magnetization, samples were AF demagnetized to $100 \mathrm{mT}$ before each isothermal remanent magnetization (IRM) treatment. All the remanent magnetizations were determined using an AGICO JR-6 spinner magnetometer.
IRM was acquired along $\mathrm{z}$ at 18 steps of $1,2,5,10,20,25$, $30,40,50,60,80,100,120,150,200,300,500,1000 \mathrm{mT}$ using an ASC-Scientific IM-10-30 impulse magnetizer. AF demagnetization was carried out at 15 steps of 1.0, 2.5, 5.0, 7.5, 10.0, 12.5, 15.0, 20.0, 25.0, 30.0, 40.0, 45.0, 50.0, 60.0, and $80.0 \mathrm{mT}$ using an AGICO LDA5 AF demagnetizer. On completion of AF demagnetization of IRM, IRM was produced again by exposing samples in a field of $1 \mathrm{~T}$. Then, back-field IRM was applied along negative $\mathrm{z}$ at 18 steps of 1 , $2,5,10,20,25,30,40,50,60,80,100,120,150,200,300$, $500,1000 \mathrm{mT}$. Note that IRM was produced along positive $\mathrm{z}$, while back-field IRM was applied along negative $\mathrm{z}$, to avoid the possible effect of remanence anisotropy.

All the samples showed saturation by $300 \mathrm{mT}$, hence the IRM applied at $1 \mathrm{~T}$ can be treated as saturation IRM (SIRM). Classical backward S-ratio compares the SIRM acquired in a saturation field (e.g., $1 \mathrm{~T}$ ) with the IRM in a smaller backfield (e.g., $-300 \mathrm{mT}$ ) as $S=$ IRM $_{-0.3 \mathrm{~T}}$ /SIRM (Stober and Thompson 1979). Revised backward $S$-ratio was modified

Table 1 Magnetic Properties of 26 Soil Samples

\begin{tabular}{|c|c|c|c|c|c|c|c|c|c|c|c|c|}
\hline Sample & $\chi_{\mathrm{fd}}(\%)$ & $\chi_{\mathrm{ARM}}\left(10^{-5} \mathrm{SI}\right)$ & MAF (mT) & $B_{\mathrm{cr}}(\mathrm{mT})$ & $S_{0.1 \mathrm{~T}}$ & $S_{-0.1 \mathrm{~T}}$ & $S_{-0.3 \mathrm{~T}}$ & HIRM & MIRM & $\mathrm{MDF}(\mathrm{mT})$ & $B_{\mathrm{R}}(\mathrm{mT})$ & $P$ \\
\hline GCA01 & 1.68 & 36.8 & 61.0 & 40.5 & 0.691 & 0.778 & 0.959 & 0.041 & 0.182 & 12.9 & 31.0 & 0.236 \\
\hline GCA05 & 1.63 & 36.4 & 69.2 & 47.5 & 0.663 & 0.779 & 0.950 & 0.008 & 0.214 & 12.4 & 32.8 & 0.242 \\
\hline GCA08 & 2.11 & 36.7 & 68.7 & 38.5 & 0.699 & 0.793 & 0.991 & 0.009 & 0.198 & 14.4 & 34.5 & 0.256 \\
\hline GCA15 & 0.84 & 146.6 & 57.6 & 31.8 & 0.745 & 0.765 & 0.938 & 0.034 & 0.201 & 8.1 & 21.1 & 0.179 \\
\hline GCA26 & 3.66 & 21.7 & 60.2 & 39.3 & 0.638 & 0.761 & 0.940 & 0.014 & 0.225 & 19.6 & 36.2 & 0.303 \\
\hline GCA37 & 3.88 & 17.1 & 77.5 & 38.2 & 0.638 & 0.777 & 0.957 & 0.016 & 0.208 & 20.4 & 42.8 & 0.261 \\
\hline GCB11 & 1.20 & 38.0 & 79.4 & 60.1 & 0.629 & 0.683 & 0.989 & 0.011 & 0.306 & 45.2 & 64.0 & 0.394 \\
\hline GCB18 & 4.09 & 58.4 & 57.8 & 29.6 & 0.717 & 0.799 & 0.965 & 0.035 & 0.166 & 23.9 & 32.4 & 0.316 \\
\hline GCB29 & 4.00 & 13.3 & 98.9 & 30.8 & 0.502 & 0.794 & 0.954 & 0.046 & 0.160 & 8.5 & 27.7 & 0.154 \\
\hline GCC01 & 1.37 & 56.2 & 57.9 & 36.4 & 0.805 & 0.856 & 0.973 & 0.027 & 0.117 & 12.4 & 28.1 & 0.218 \\
\hline GCC06 & 1.20 & 109.2 & 53.7 & 37.3 & 0.783 & 0.834 & 0.978 & 0.022 & 0.144 & 17.4 & 30.3 & 0.248 \\
\hline GCC12 & 3.66 & 25.2 & 49.7 & 35.0 & 0.787 & 0.783 & 0.939 & 0.027 & 0.190 & 13.1 & 28.9 & 0.258 \\
\hline GCC31 & 3.21 & 63.6 & 45.9 & 29.4 & 0.785 & 0.865 & 0.979 & 0.021 & 0.113 & 7.4 & 23.0 & 0.228 \\
\hline GCD04 & 0.93 & 79.3 & 62.0 & 29.9 & 0.682 & 0.855 & 0.946 & 0.054 & 0.091 & 7.4 & 25.6 & 0.208 \\
\hline GCD11 & 1.96 & 57.1 & 53.3 & 33.8 & 0.748 & 0.839 & 0.972 & 0.028 & 0.132 & 15.4 & 27.7 & 0.286 \\
\hline GCD15 & 4.17 & 54.6 & 39.3 & 29.0 & 0.834 & 0.864 & 0.967 & 0.033 & 0.103 & 11.0 & 23.2 & 0.239 \\
\hline GCD31 & 0.99 & 105.3 & 33.7 & 27.1 & 0.813 & 0.864 & 0.960 & 0.040 & 0.096 & 8.2 & 19.1 & 0.231 \\
\hline GCD40 & 1.13 & 115.2 & 39.6 & 23.7 & 0.728 & 0.848 & 0.948 & 0.052 & 0.100 & 10.4 & 21.6 & 0.254 \\
\hline GCE01 & 1.26 & 66.3 & 53.9 & 33.3 & 0.784 & 0.864 & 0.981 & 0.019 & 0.117 & 13.0 & 26.3 & 0.222 \\
\hline GCE18 & 3.33 & 29.1 & 48.5 & 30.0 & 0.732 & 0.835 & 0.981 & 0.045 & 0.121 & 13.8 & 26.7 & 0.265 \\
\hline GCE30 & 4.29 & 27.9 & 51.8 & 29.7 & 0.686 & 0.896 & 0.972 & 0.017 & 0.087 & 11.1 & 23.3 & 0.251 \\
\hline GCE44 & 1.00 & 24.1 & 35.9 & 25.2 & 0.806 & 0.889 & 0.984 & 0.016 & 0.095 & 9.8 & 20.5 & 0.258 \\
\hline GCF01 & 1.15 & 41.7 & 55.1 & 32.5 & 0.720 & 0.825 & 0.970 & 0.030 & 0.145 & 9.3 & 24.2 & 0.198 \\
\hline GCF15 & 2.55 & 28.2 & 48.4 & 29.3 & 0.713 & 0.850 & 0.939 & 0.061 & 0.090 & 5.4 & 20.3 & 0.158 \\
\hline GCF35 & 0.57 & 85.1 & 49.8 & 29.0 & 0.739 & 0.855 & 0.961 & 0.057 & 0.088 & 6.3 & 20.6 & 0.203 \\
\hline GCF36 & 1.67 & 60.6 & 52.8 & 34.0 & 0.725 & 0.846 & 0.982 & 0.018 & 0.136 & 18.7 & 30.8 & 0.304 \\
\hline
\end{tabular}

$\chi_{\mathrm{fd}}(\%)=\left[\left(\chi_{\mathrm{lf}}-\chi_{\mathrm{hf}}\right) / \chi_{\mathrm{lf}}\right] \times 100 ; \chi_{A R M}$ susceptibility of anhysteretic remanent magnetization; MAF median acquisition field; $B_{c r}$ coercivity of remanence; $S_{0.1 \mathrm{~T}}=\mathrm{IRM}_{0.1 \mathrm{~T}} / \mathrm{SIRM} ; S_{-0.1 \mathrm{~T}}=0.5\left(1-\mathrm{IRM}_{-0.1 \mathrm{~T}} / \mathrm{SIRM}\right) ; S_{-0.3 \mathrm{~T}}=0.5\left(1-\mathrm{IRM}_{-0.3 \mathrm{~T}} / \mathrm{SIRM}\right) ; \mathrm{HIRM}=0.5(\mathrm{SIRM}+\mathrm{IRM}-0.3 \mathrm{~T}) ;$ $\mathrm{MIRM}=0.5($ SIRM + IRM $-0.1 \mathrm{~T})-$ HIRM; $M D F$ median destructive field; $B_{R}$ Crossover field; $P$ Crossover point 
as $S_{-0.1 \mathrm{~T}}=0.5\left(1-\mathrm{IRM}_{-0.1 \mathrm{~T}} / \mathrm{SIRM}\right)$ and $S_{-0.3 \mathrm{~T}}=0.5$ $\left(1-\right.$ IRM $_{-0.3 \mathrm{~T}}$ /SIRM) (Bloemendal et al. 1992; Liu et al. 2007). While $S$ varies from -1 to $+1, S_{-0.1 \mathrm{~T}}$ or $S_{-0.3 \mathrm{~T}}$ varies from 0 to +1 . In particular, it has been widely used that values of $S_{-0.3 \mathrm{~T}}$ in percent represent the amount of low coercivity fraction in samples. The forward $S$-ratio compares the SIRM acquired in a saturation field (i.e., $1 \mathrm{~T}$ ) with the IRM in a smaller forward field (e.g., $100 \mathrm{mT}$ ) as $S_{0.1 \mathrm{~T}}=\mathrm{IRM}_{0.1 \mathrm{~T}} /$ SIRM (Kruiver and Passier 2001). A complementary statistical treatment and physical rationale on the use of S-ratio are beyond the scope of this study, but were provided by Liu et al. (2007) and by Heslop (2009), respectively. In addition to the various forms of $S$ ratio, two other coercivityrelated parameters were useful (e.g., Bloemendal et al. 1992; Yamazaki et al. 2003). First, high-coercivity fraction of IRM (HIRM) was defined as HIRM $=0.5\left(\right.$ SIRM + IRM $\left._{-0.3 \mathrm{~T}}\right)$. Second, medium-coercivity fraction of IRM (MIRM) was defined as MIRM $=0.5\left(\right.$ SIRM $^{-I_{R M}}$ - $\left.0.1 \mathrm{~T}\right)-$ HIRM.

On completion of all the field-treated experiments, representative cubes were dismantled for further analysis. Magnetic particles were separated using a hand magnet. Half of the extracted magnetic particles were examined under the microscope. Plastered caps were employed for the remaining half of the extracted magnetic particles. These caps were then one-inch cut for thermal treatment. At last, stepwise thermal demagnetization of 3-axis IRM (Lowrie 1990) was applied to the representative samples on the basis of their IRM behavior. IRMs were sequentially produced along the three mutually perpendicular directions using an ASC-Scientific IM-10-30 impulse magnetizer. Sequential fields used to produce a composite IRM were $1.2,0.4$, and $0.12 \mathrm{~T}$ along $\mathrm{z}$-axis, $\mathrm{x}$-axis, and $\mathrm{y}$-axis, respectively.

\section{Statistical analysis}

Relationship between magnetic parameters in the topsoil was studied by means of Pearson correlation analyses. The Pearson correlation coefficient $(R)$ was used to quantify the degree of linear relation in a bivariate system (Table 2).

Table 2 also lists correlation coefficient of determination $\left(R^{2}\right)$ between pairs of twelve rock magnetic factors including $\chi_{\mathrm{fd}}, \chi_{\mathrm{ARM}}, \mathrm{MAF}, B_{\mathrm{cr}}$, forward $S$ ratio at $0.1 \mathrm{~T}\left(S_{0.1 \mathrm{~T}}\right)$, backward $S$ ratio at $-0.1 \mathrm{~T}\left(S_{-0.1 \mathrm{~T}}\right)$ and at $-0.3 \mathrm{~T}\left(S_{-0.3 \mathrm{~T}}\right)$, HIRM, MIRM, MDF, crossover field $\left(B_{\mathrm{R}}\right)$, and crossover point $(P)$. Although crossover point has been abbreviated as $R$ in rock magnetism and environmental magnetism communities, we used $P$ to avoid confusion with the Pearson correlation coefficient $(R)$.

\section{Results}

\section{Spatial distribution of magnetic susceptibility}

The magnetic susceptibility values ranged from 8.6 to $71.7 \times 10^{-5} \mathrm{SI}$ in the soils of profile S1 (Fig. 2). The mean and median magnetic susceptibility of $\mathrm{S} 1$ were $29.2 \pm 13.1 \times 10^{-5} \mathrm{SI}$ and $28.6 \times 10^{-5} \mathrm{SI}$, respectively. Two highest peaks occurred at 11.6 and $14.5 \mathrm{~m}$ away from the street (Fig. 2). Magnetic susceptibility of profiles S2 decayed to lower value from 0 to $55 \mathrm{~m}$ towards the south and then slightly enhanced from 55 to $100 \mathrm{~m}$ (Fig. 2). The mean and median magnetic susceptibility of S2 were $25.4 \pm 8.6 \times 10^{-5}$ SI and $21.4 \times 10^{-5} \mathrm{SI}$, respectively. The profile S3 showed a peak at $62.5 \mathrm{~m}$ towards the south (Fig. 2). The mean and median magnetic susceptibility of S3 were $25.2 \pm 10.4 \times 10^{-5}$ SI and $19.5 \times 10^{-5} \mathrm{SI}$, respectively. The coefficient of variation (CV) or relative standard deviation (RSD) is a percentage ratio of the standard deviation to the mean. The $\mathrm{CV}$ or RSD for S1, S2, S3 were 45.0, 33.7, 41.4\%, respectively.

Three profiles towards the North appeared to be fairly similar with one another (Fig. 2). They all showed decreasing trend of magnetic susceptibility from 0 to $55 \mathrm{~m}$, and then jumped to higher values (Fig. 2). The magnetic susceptibility values ranged from 13.2 to $53.5 \times 10^{-5} \mathrm{SI}$ in the soils of profile N1 (Fig. 2). The mean and median magnetic susceptibility were $29.9 \pm 9.6 \times 10^{-5}$ SI and $29.0 \times 10^{-5} \mathrm{SI}$ for N1, 27.1 $\pm 9.8 \times 10^{-5} \mathrm{SI}$ and $25.2 \times 10^{-5} \mathrm{SI}$ for N2, and $30.2 \pm 8.1 \times 10^{-5}$ SI and $28.3 \times 10^{-5}$ SI for N3, respectively. The CV or RSD for N1, N2, N3 were 31.9, 36.2, 26.7\%, respectively. Values of CV or RSD were smaller for northern profiles than those for southern profiles, as the variation of magnetic susceptibility was more substantial in southern profiles (Fig. 2).

On the basis of magnetic susceptibility collected from six profiles, two dimensional map of magnetic susceptibility was constructed (Fig. 3). We found that the 5 and $95 \%$ percentile of magnetic susceptibility from a total of 238 readings were $10 \times 10^{-5} \mathrm{SI}$ and $50 \times 10^{-5} \mathrm{SI}$, respectively. Hence, these values were used as the lower and upper bound of 20-step contours (Fig. 3). A contour map was produced from Grapher 10.5 with the lowest available data smoothing (i.e., smoothing factor $=1$ ). It is evident that high values of magnetic susceptibility were narrowly concentrated adjacent to the street (Fig. 3). Magnetic susceptibility decreased away from the street to $55 \mathrm{~m}$ distance (Fig. 3). Magnetic susceptibility began to increase again, reaching 30 to $40 \times 10^{-5} \mathrm{SI}$ in southern profiles and 30 to $50 \times 10^{-5} \mathrm{SI}$ in northern profiles (Fig. 3). 
Table 2 Pearson correlation coefficients between magnetic parameters $(N=26)$

\begin{tabular}{|c|c|c|c|c|c|c|c|c|c|c|c|c|}
\hline Factors & $\chi_{\mathrm{fd}}$ & $\chi_{\mathrm{ARM}}$ & MAF & $B_{\text {cr }}$ & $S_{0.1 \mathrm{~T}}$ & $S_{-0.1 \mathrm{~T}}$ & $S_{-0.3 \mathrm{~T}}$ & HIRM & MIRM & MDF & $B_{\mathrm{R}}$ & $P$ \\
\hline \multirow[t]{3}{*}{$\chi_{\mathrm{fd}}$} & & $R=-0.57$ & 0.20 & -0.09 & -0.27 & -0.06 & -0.12 & -0.12 & 0.09 & 0.08 & 0.10 & 0.11 \\
\hline & & $\mathrm{R}^{2}=0.33$ & 0.04 & 0.01 & 0.08 & $<0.01$ & 0.01 & 0.01 & 0.01 & 0.01 & 0.01 & 0.01 \\
\hline & & $p<0.01$ & 0.32 & 0.66 & 0.17 & 0.76 & 0.56 & 0.56 & 0.66 & 0.69 & 0.63 & 0.59 \\
\hline \multirow[t]{3}{*}{$\chi_{\text {ARM }}$} & & & -0.38 & -0.28 & 0.43 & 0.17 & -0.13 & 0.29 & -0.24 & -0.21 & -0.35 & -0.18 \\
\hline & & & 0.15 & 0.08 & 0.18 & 0.03 & 0.02 & 0.09 & 0.06 & 0.04 & 0.12 & 0.03 \\
\hline & & & 0.05 & 0.17 & 0.03 & 0.39 & 0.51 & 0.15 & 0.24 & 0.30 & 0.08 & 0.38 \\
\hline \multirow[t]{3}{*}{ MAF } & & & & 0.58 & -0.86 & -0.66 & -0.05 & -0.20 & 0.64 & 0.39 & 0.62 & 0.03 \\
\hline & & & & 0.34 & 0.74 & 0.43 & $<0.01$ & 0.04 & 0.41 & 0.15 & 0.38 & $<0.01$ \\
\hline & & & & $<0.01$ & $<0.01$ & $<0.01$ & 0.81 & 0.33 & $<0.01$ & 0.05 & $<0.01$ & 0.87 \\
\hline \multirow[t]{3}{*}{$B_{\text {cr }}$} & & & & & -0.39 & -0.79 & 0.17 & -0.55 & 0.85 & 0.76 & 0.88 & 0.53 \\
\hline & & & & & 0.15 & 0.62 & 0.03 & 0.30 & 0.72 & 0.57 & 0.77 & 0.28 \\
\hline & & & & & 0.05 & $<0.01$ & 0.39 & $<0.01$ & $<0.01$ & $<0.01$ & $<0.01$ & $<0.01$ \\
\hline \multirow[t]{3}{*}{$S_{0.1 \mathrm{~T}}$} & & & & & & 0.56 & 0.23 & $<0.01$ & -0.49 & -0.28 & -0.48 & -0.04 \\
\hline & & & & & & 0.31 & 0.05 & $<0.01$ & 0.24 & 0.08 & 0.23 & $<0.01$ \\
\hline & & & & & & $<0.01$ & 0.26 & 0.99 & 0.01 & 0.16 & 0.01 & 0.86 \\
\hline \multirow[t]{3}{*}{$S_{-0.1 \mathrm{~T}}$} & & & & & & & 0.19 & 0.28 & -0.96 & -0.67 & -0.79 & -0.41 \\
\hline & & & & & & & 0.04 & 0.08 & 0.93 & 0.45 & 0.62 & 0.17 \\
\hline & & & & & & & 0.36 & 0.17 & $<0.01$ & $<0.01$ & $<0.01$ & 0.04 \\
\hline \multirow[t]{3}{*}{$S_{-0.3 \mathrm{~T}}$} & & & & & & & & -0.47 & -0.04 & 0.36 & 0.26 & 0.42 \\
\hline & & & & & & & & 0.22 & $<0.01$ & 0.13 & 0.07 & 0.17 \\
\hline & & & & & & & & 0.02 & 0.86 & 0.07 & 0.20 & 0.03 \\
\hline \multirow[t]{3}{*}{ HIRM } & & & & & & & & & -0.53 & -0.49 & -0.51 & -0.54 \\
\hline & & & & & & & & & 0.28 & 0.24 & 0.26 & 0.29 \\
\hline & & & & & & & & & $<0.01$ & 0.01 & $<0.01$ & $<0.01$ \\
\hline \multirow[t]{3}{*}{ MIRM } & & & & & & & & & & 0.73 & 0.84 & 0.51 \\
\hline & & & & & & & & & & 0.53 & 0.71 & 0.26 \\
\hline & & & & & & & & & & $<0.01$ & $<0.01$ & $<0.01$ \\
\hline \multirow[t]{3}{*}{ MDF } & & & & & & & & & & & 0.93 & 0.87 \\
\hline & & & & & & & & & & & 0.86 & 0.75 \\
\hline & & & & & & & & & & & $<0.01$ & $<0.01$ \\
\hline \multirow[t]{3}{*}{$B_{\mathrm{R}}$} & & & & & & & & & & & & 0.72 \\
\hline & & & & & & & & & & & & 0.52 \\
\hline & & & & & & & & & & & & $<0.01$ \\
\hline
\end{tabular}

$\chi_{\mathrm{fd}}(\%)=\left[\left(\chi_{\mathrm{lf}}-\chi_{\mathrm{hf}}\right) \chi_{\mathrm{lf}}\right] \times 100 ; \chi_{A R M}$ susceptibility of anhysteretic remanent magnetization; MAF median acquisition field; $B_{c r}$ coercivity of remanence; $S_{0.1 \mathrm{~T}}=\mathrm{IRM}_{0.1 \mathrm{~T}}$ /SIRM; $S_{-0.1 \mathrm{~T}}=0.5\left(1-\mathrm{IRM}_{-0.1 \mathrm{~T}} / \mathrm{SIRM}\right) ; S_{-0.3 \mathrm{~T}}=0.5\left(1-\mathrm{IRM}_{-0.3 \mathrm{~T}} / \mathrm{SIRM}\right) ; \mathrm{HIRM}=0.5\left(\mathrm{SIRM}+\mathrm{IRM}_{-0.3 \mathrm{~T}}\right)$; $\mathrm{MIRM}=0.5\left(\mathrm{SIRM}+\mathrm{IRM}_{-0.1 \mathrm{~T}}\right)-\mathrm{HIRM} ; M D F$ median destructive field; $B_{R}$ Crossover field; $P$ Crossover point; $R$ Pearson correlation coefficient; $R^{2}$ correlation coefficient of determination; $p$ : significance level (in bold)

\section{Grain proxy}

The mean of $\chi_{\mathrm{fd}}$ was $2.21 \pm 1.27 \%$, with only four samples exceeding $4 \%$ (Table 1$)$. The low $\chi_{\mathrm{fd}}$ values $(<5 \%)$ indicate that SP grains do not exist in considerable amounts in the topsoil of studied samples (e.g., Dearing et al. 1996; Magiera et al. 2011, 2013). Such low $\chi_{\mathrm{fd}}$ was the characteristics of roadside dusts (e.g., Shilton et al. 2005; Yang et al.
2010; Bourliva et al. 2016). $\chi_{\mathrm{fd}}$ and $\chi_{\mathrm{lf}}$ were approximately inversely correlated (Fig. 4a), consistent with the frequency dependence of magnetic susceptibility observed for ferrimagnetic grains (Dearing et al. 1996).

Plots of $\chi_{\text {ARM }}$ versus $\chi_{\mathrm{lf}}$ (Fig. $4 \mathrm{~b}$ ) were useful to detect changes in the relative grain-size of ferrimagnetic grains in natural materials (King et al. 1982). Observed data fell in the range of 0.1-20 $\mu \mathrm{m}$ magnetite particles (Fig. $4 \mathrm{~b}$ ). 


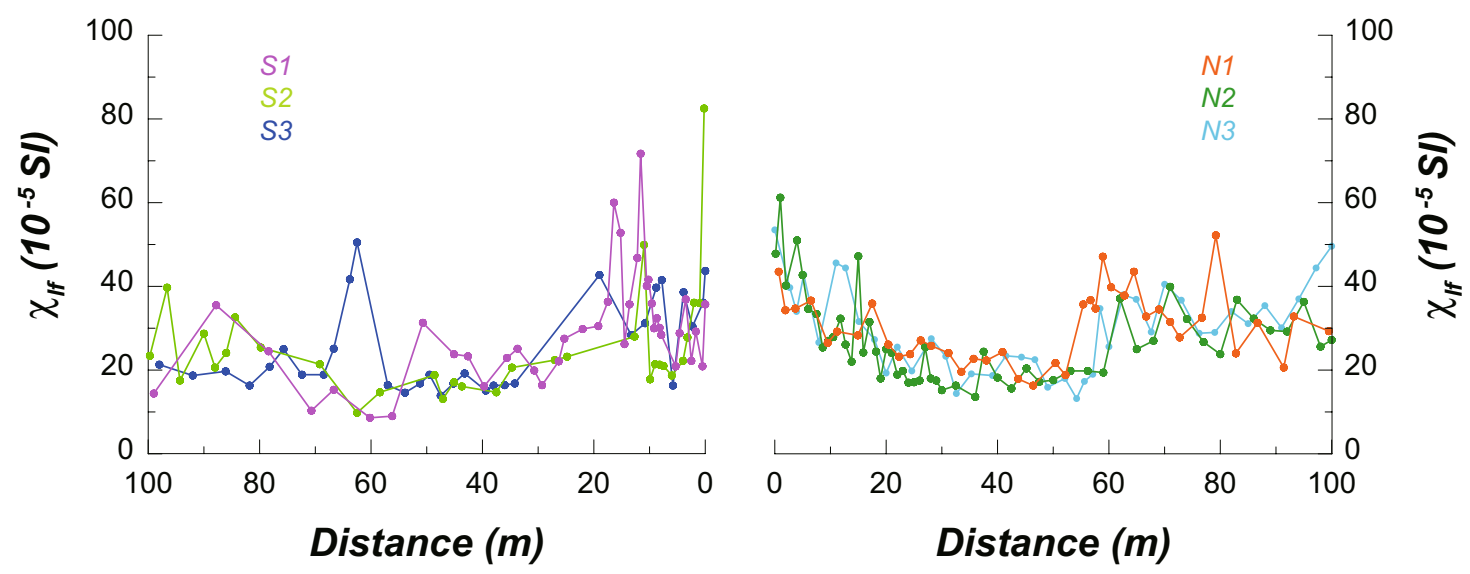

Fig. 2 Profiles of soil-surface magnetic susceptibility. A total of 238 readings were taken ( 40 from S1, 31 from S2, 32 from S3, 40 from N1, 54 from N2, 41 from N3)

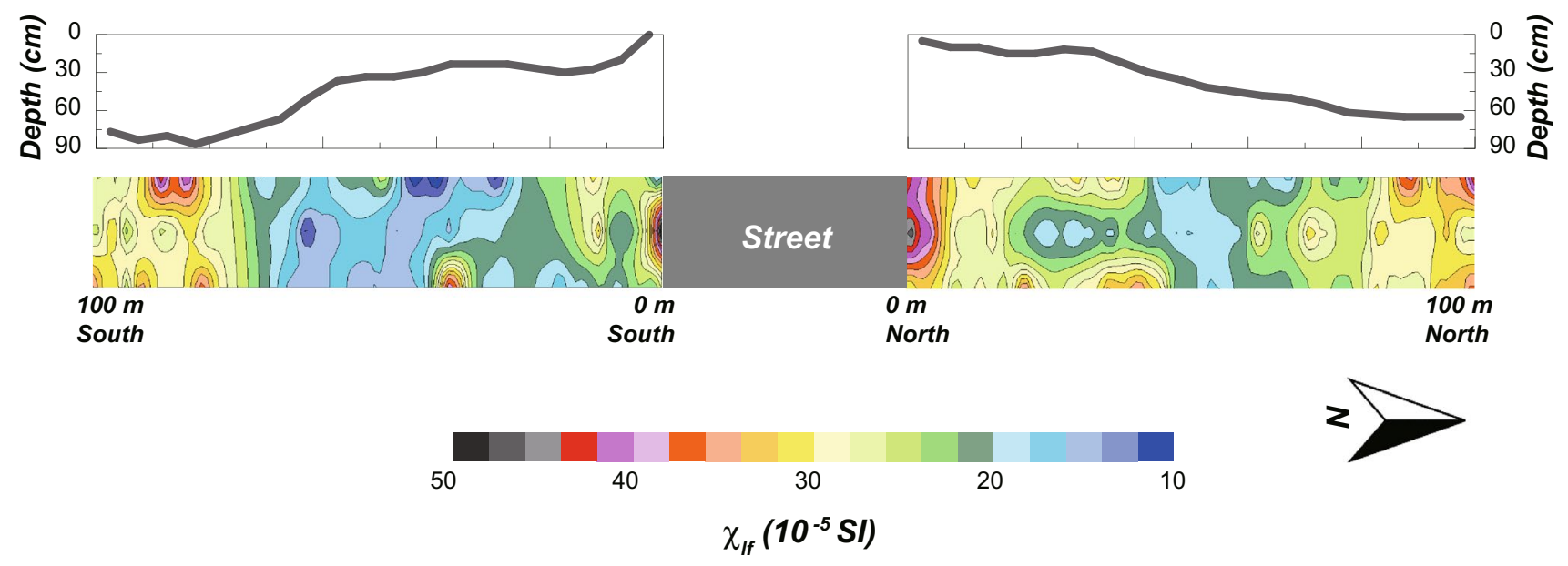

Fig. 3 Contour plot of magnetic susceptibility values in the topsoil. Elevation (i.e., depth) profile along the transect was provided as an inset
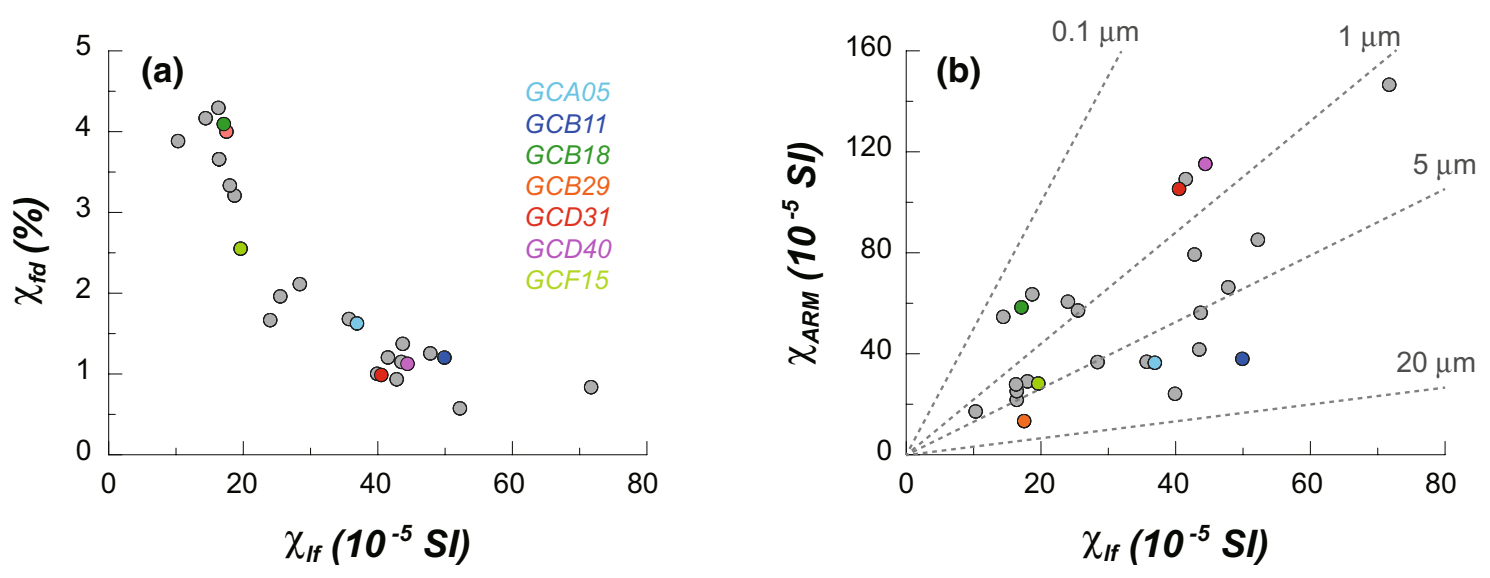

Fig. 4 a Plots of $\chi_{\mathrm{fd}}$ percentage versus $\chi_{\mathrm{lf}}$. b Bivariate plot of $\chi_{\mathrm{AMS}}$ versus $\chi_{\mathrm{lf}}$. Reference lines were retrieved from King et al. (1982) 

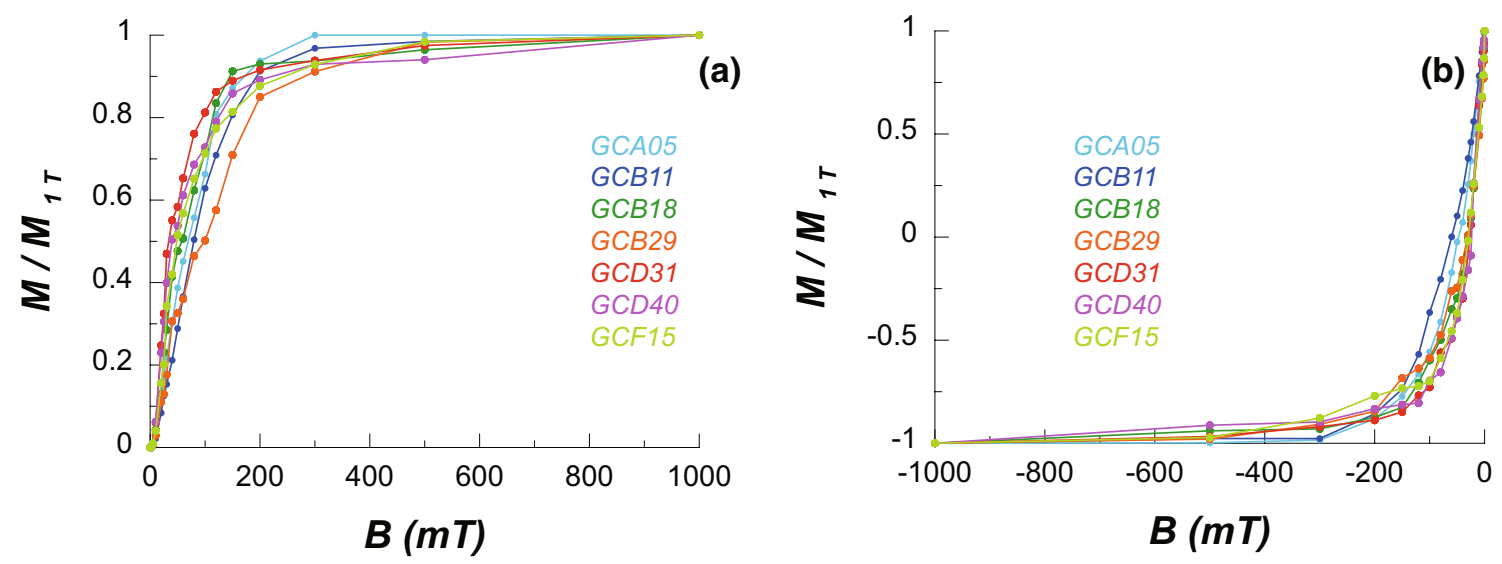

Fig. 5 a Normalized curves for the acquisition of IRM. b Back-field decay of saturation IRM

\section{Isothermal remanent magnetization}

The IRM acquisition curves (Fig. 5) were rapidly increasing at low fields $(<100 \mathrm{mT})$. They reached saturation by $300 \mathrm{mT}$, indicating a predominance of low-coercivity Feoxides (Fig. 5a). The median acquisition field (MAF) was defined as the impulse field that reached the 50\% of SIRM. Values of MAF varied from $33.7 \mathrm{mT}$ (GCD31) to $98.9 \mathrm{mT}$ (GCB29), with a mean of $56.2 \pm 14.2 \mathrm{mT}$ (Table 1$)$.

The coercivity of remanence $\left(B_{\mathrm{cr}}\right)$ was determined from the back-field IRM curves (Fig. 5b). Values of $B_{\text {cr }}$ varied from $23.7 \mathrm{mT}$ (GCD40) to $60.1 \mathrm{mT}$ (GCB11), with a mean of $33.9 \pm 7.5 \mathrm{mT}$ (Table 1). Values of $S_{-0.1 \mathrm{~T}}$ ranged from 0.683 (GCB11) to 0.896 (GCE30), with a mean of $0.823 \pm 0.049$ (Table 1). Values of $S_{-0.3 \mathrm{~T}}$ were larger than those of $S_{-0.1 \mathrm{~T}}$, with a mean of $0.961 \pm 0.011$ (Table 1). The HIRM reflects the amount of hard magnetic phase (hematite

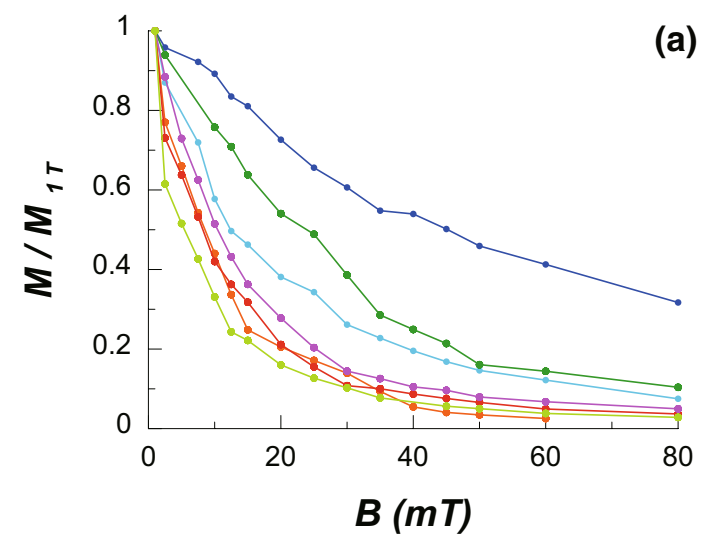

Fig. 6 Composite diagrams showing a AF demagnetization of saturation IRM, b difference between normalized AF demagnetization curves between observed $M_{\mathrm{BF}}$ and synthesized $M_{\mathrm{BF}}{ }^{*}$. Back-field coer- or goethite) in mineral mixtures that also contain magnetite (Liu et al. 2007). High $S$-ratios $\left(S_{-0.1 \mathrm{~T}}\right.$ and $\left.S_{-0.3 \mathrm{~T}}\right)$ and low HIRM indicate a prominence of low-coercivity magnetic particulates (Table 1). The MIRM reflects the amount of medium-coercivity magnetic phase in mineral mixtures. The MIRM varied from 0.087 (GCE30) to 0.306 (GCB11), with a mean of $0.147 \pm 0.055$ (Table 1 ).

The median destructive field (MDF) was defined as the AF that reduced the NRM by $50 \%$ (Fig. 6a, Table 1). The MDF thus reflects the coercivity spectra of magnetic particles. Values of MDF ranged from $5.4 \mathrm{mT}$ (GCF15) to $45.2 \mathrm{mT}$ (GCB11), with a mean of $13.7 \pm 7.9 \mathrm{mT}$ (Table 1). Intersection point between IRM acquisition and IRM decay curves lied well below 0.5 , indicating some degree of grain interaction (Table 1).

One set of coercivity spectra $\left(M_{\mathrm{AF}}\right)$ were constructed from stepwise AF demagnetization of SIRM. Another

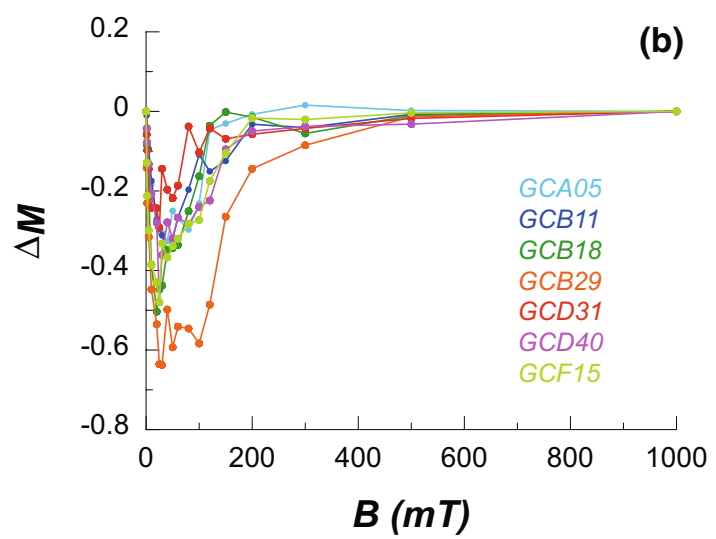

civity spectra were constructed from $\mathrm{AF}$ demagnetization of SIRM $\left(M_{\mathrm{AF}}\right)$ with a relation of $M_{\mathrm{BF}} *=1-2 M_{\mathrm{AF}}$ 
independent set of coercivity spectra $\left(M_{\mathrm{BF}}\right)$ can be obtained during back-field IRM decay curves. According to Wohlfarth theory (Wohlfarth 1958), non-interacting single domain (SD) particles satisfy the relation of $M_{\mathrm{BF}}{ }^{*}=1-2$ $M_{\mathrm{AF}}$. When $\mathrm{M}_{\mathrm{BF}}$ was plotted against $M_{\mathrm{AF}}$, ideal non-interacting SD grains would yield a slope of -2 with a y-intercept at +1 (Henkel 1964). In reality, observed $M_{\mathrm{BF}}$ and synthesized $M_{\mathrm{BF}} *$ from $M_{\mathrm{AF}}$ would be different unless samples are free of interaction. The difference between observed $M_{\mathrm{BF}}$ and synthesized $M_{\mathrm{BF}} *$ was represented as $\Delta M$ (e.g., Mayo et al. 1990, 1991a, b; Speliotis and Lynch 1991). It is common to observe negative $\Delta M$ in most field intervals as interaction tends to lower magnetization (Petrovský et al. 1993). Although rare, positive $\Delta M$ is possible in some field intervals, where positive interaction induces enhanced magnetization. In the present study, we found negative $\Delta M$ from all samples (Fig. 6b). It should be noted that sample GCB29 showed the deepest negative $\Delta M$ and the largest MAF, indicative of strongly interacting fine-grained magnetic particles in this sample (Fig. 6b, Table 1).

The maximum unblocking temperatures of composite IRMs (Lowrie 1990) were $580{ }^{\circ} \mathrm{C}$ which is the Curie temperature of magnetite, suggesting that the magnetic mineralogy was dominated by magnetite (Fig. 7a). Under the microscope, we found two different types of magnetic material. About two thirds of magnetic particles were angular in

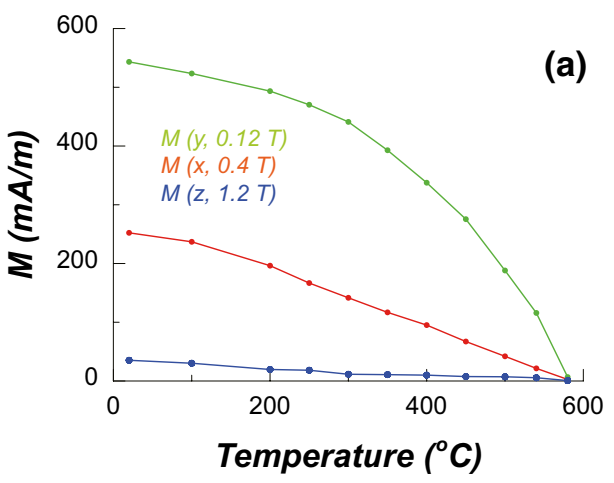

(b)
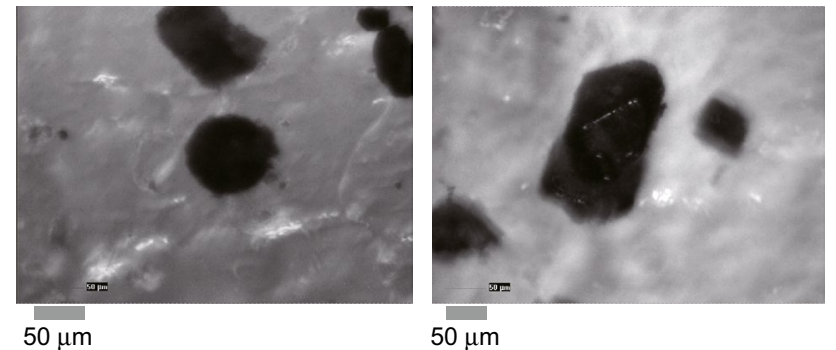

Fig. 7 a Thermal demagnetization curves of a three-component (hard, medium, soft) IRM (Lowrie 1990), indicating a presence of magnetite. b Representative images of spherical and angular magnetic particulates shape, with various sizes from 20 to $400 \mu \mathrm{m}$ (Fig. 7b). The presence of lithogenic magnetite is clearly shown by angular magnetite with octahedral morphology (Fig. 7b). Other particles showed spherical morphologies with relative uniform diameters of about $50 \mu \mathrm{m}$ or less (Fig. $7 \mathrm{~b}$ ).

\section{Discussion}

\section{Spatial distribution of magnetic susceptibility}

A generally higher level of magnetic susceptibility was observed near the roadside base of profiles (Figs. 2 and 3). Compared to the peripheries of the studied area, magnetic susceptibilities were much more pronounced getting closer to the main street. It is natural to anticipate that magnetic susceptibility decreases with distance from the input source (e.g., Hoffmann et al. 1999). The highest magnetic susceptibility was observed within a distance of a few meters from the main street. Such characteristics can be related to the emission of the traffic pollution produced by vehicular engine emissions (e.g., Zechmeister et al. 2005; Bućko et al. 2010; Werkenthin et al. 2014; Wawer et al. 2015; Ma et al. 2016; Nikolaeva et al. 2017; Pierwola et al. 2020). Magnetic enhancement getting closer to the main street decayed exponentially from 0 to $55 \mathrm{~m}$ with respect to the distance (Figs. 2 and 3) due to magnetic grain size or the amount of magnetic particles with distances away from the source.

In the present study, magnetic susceptibility was lower away from the road, because air circulation was intense along the river, less efficient in settling of magnetic particles on the grassland. The lowest values of magnetic susceptibility occurred about $55 \mathrm{~m}$ away from the main street and a systematic increase of susceptibility towards the roads was observed (Fig. 2). Perhaps, the air flow became less significant to settle magnetic particles with increasing distance from the road. It should be noted that magnetic susceptibility enhanced again from 55 to $100 \mathrm{~m}$ to form local magnetic highs around the periphery (Figs. 2 and 3). The localized, narrow and linear anomalies represent enhancement of magnetic susceptibility parallel to the street alignment, typical characteristics of traffic-related particles (Hoffmann et al. 1999; Zechmeister et al. 2005; Bućko et al. 2010; Werkenthin et al. 2014; Ma et al. 2016; Nikolaeva et al. 2017; Pierwola et al. 2020).

A few magnetic hotspots around the periphery with intensities of magnetic susceptibility near or over $50 \times 10^{-5}$ SI might represent the possible input of magnetic material from the nearby alleys if we stick only to the traffic sources (Figs. 2 and 3). However, more realistic explanation would be the difference in topographic elevation and surface morphology. Indeed, local magnetic highs are located in lower 
elevation, where decline trend of elevation stops (Fig. 3). It is possible that magnetic particles were continuously accumulated in these low elevations over time.

In nature, anthropogenic pollutants occurred in solid, liquid, and gas phases or a combination of multiple phases. Because of on-going water cycling events (i.e., rain or snow), fluidal phases of pollutants were washed away and/ or penetrated into the ground. As a result, only the solid phase will dominate the magnetic signal in the topsoil. The solid phase may include pollutants produced mostly by abrasion and corrosion. On the basis of crystal morphology, it is likely that angular iron-rich oxide particles were possibly originated from traffic-related process or natural source (Fig. 7b). It was well documented that vehicles produce angular magnetite particles via non-exhaust emissions as a result of abrasion of brake linings, as well as the abrasion or corrosion of vehicle engine and body work (e.g., Matzka and Maher 1999; Bućko et al. 2010; Bourliva et al. 2016). Particles in rounded shapes were unlikely to represent natural minerals, but were produced by fossil fuel combustion process considering their morphological characteristics (Fig. 7b). Iron-oxide spherules are definitely high-temperature origin, characteristic of vehicle exhaust emission or fly ash particles derived from fossil fuel combustion process (e.g., Spiteri et al. 2005; Goodarzi 2006; Jordanova et al. 2008). These pollutants are probably transported from western coastal industrial areas of South Korea and eastern coastal industrial areas of China (e.g., Kim et al. 2012; Baatar et al. 2017; Ha et al. 2017).

Magnetic minerals are inherited from the parent materials of soils throughout the process of weathering and pedogenesis. Urbanization process accompanies steady accumulation of heavy metals in association with magnetic particles to the soils (Karimi et al. 2011; Dankoub et al. 2012). Influence of pedogenic production of secondary ferrimagnetic material also needs to be counted. Considering meteorological data (e.g., annual rainfalls) and topographic information (e.g., elevation difference), pedogenesis was possibly disturbed continuously under pasture. It should be noted that pedogenic particles are usually much smaller than angular magnetites observed in the present study (Fig. 7b), and usually regular in shape, because they were formed in natural conditions (e.g., Bućko et al. 2010, 2011; Bourliva et al. 2016, 2018). Hence, pedogenic production of secondary ferrimagnetic material was probably insignificant, although we cannot completely rule out the possibility.

\section{Rock magnetic characteristics}

Because weak-field properties (e.g., $\chi_{\mathrm{ARM}}$ and $\chi_{\mathrm{fd}}$ ) are sensitive to fine-grained ferrimagnetic particles, they have been commonly used as granulometric indicators in rock magnetism and environmental magnetism. $\chi_{\mathrm{fd}}$ did not show any significant correlation with IRM-related parameters (Fig. 4), simply because our soil samples were virtually devoid of SP grains (Table 2). Similarly, $\chi_{\text {ARM }}$ lacked correlation with IRM-related parameters, also supporting near absence of extremely fine particles (Table 2). Hence, we will focus only on the mutual correlation between high-field IRM-relevant parameters.

$S$-ratios represent the fraction of lower coercivity minerals to higher coercivity minerals (e.g., Salomé and Meynadier 2004; Liu et al. 2007). Values of $S_{0.1 \mathrm{~T}}, S_{-0.1 \mathrm{~T}}$, and $\mathrm{S}_{-0.3 \mathrm{~T}}$ ranged from 0.502 to $0.834,0.683$ to 0.896 , and 0.938 to 0.991 , respectively (Table 1 ). In particular, values of $S_{-0.3 \mathrm{~T}}$ were extremely high, indicative of a low content of high coercivity minerals. This agrees well with the fact that the IRM acquisitions were saturated by $0.3 \mathrm{~T}$ in all samples (Fig. 5).

A total of 25 pairs out of 66 possible combinations yielded significant results with $p<0.01$ (Table 2). Among ten rock magnetic factors used, $B_{\mathrm{cr}}$ was chosen as the common parameters in all correlation diagrams (Fig. 8). It is evident that $B_{\text {cr }}$ showed significant correlation with seven other factors (Table 2). For instance, there is a correlation between MDF and $B_{\mathrm{cr}}\left(R^{2}=0.5711\right.$, Fig. $8 \mathrm{a}), B_{\mathrm{R}}$ and $B_{\text {cr }}\left(R^{2}=0.7711\right.$, Fig. 8b), MIRM and $B_{\text {cr }}$ $\left(R^{2}=0.7223\right.$, Fig. $\left.8 \mathrm{c}\right), P$ and $B_{\text {cr }}\left(R^{2}=0.2809\right.$, Fig. $\left.8 \mathrm{~d}\right)$, and $S_{-0.1 \mathrm{~T}}$ and $B_{\mathrm{cr}}\left(R^{2}=0.6164\right.$, Fig. 8e $)$. As the values of $R^{2}$ were relatively smaller, it must be regarded that MDF (Fig. 8a) and $P$ (Fig. 8d) as less diagnostic to $B_{\text {cr }}$ than other parameters of $B_{\mathrm{R}}$, MIRM, or $S_{-0.1 \mathrm{~T}}$. No significant correlation between $S_{-0.3 \mathrm{~T}}$ and $B_{\mathrm{cr}}\left(R^{2}=0.0303\right.$, Fig. 8f) was observed. It is apparent that $S_{-0.3 \mathrm{~T}}$ is not correlated with all other factors, simply because $S_{-0.3 \mathrm{~T}}$ was too high to show any significant trend (Table 2). Insensitivity of $S_{-0.3 \mathrm{~T}}$ in this study was somewhat anticipated as high coercivity material is nearly absent in our soil samples (Table 1).

The classical rock magnetic approach requires modification to incorporate more objective IRM unmixing analysis developed by Kruiver and Passier (2001). We applied the MaxUnMix (Maxbauer et al. 2016, 2017), which is an upgraded semi-automated version of the IRM unmixing analysis (Kruiver and Passier 2001). IRM component analysis yielded one or two magnetic components (Fig. 9). For example, sample GCD31 had $63.0 \%$ of softer component $(21.3 \mathrm{mT})$ and $37.0 \%$ of harder component (81.3 mT) (Fig. 9a). Results from GCD40 (Fig. 9b) were similar to those of GCD31. Nearly equal contribution from softer component and harder component was observed for GCA05 (Fig. 9c), GCB18 (Fig. 9d), and GCB29 (Fig. 9e). In these samples, dual coercivity peaks were more prominent (Fig. 9c-e) than those for GCD31 or 

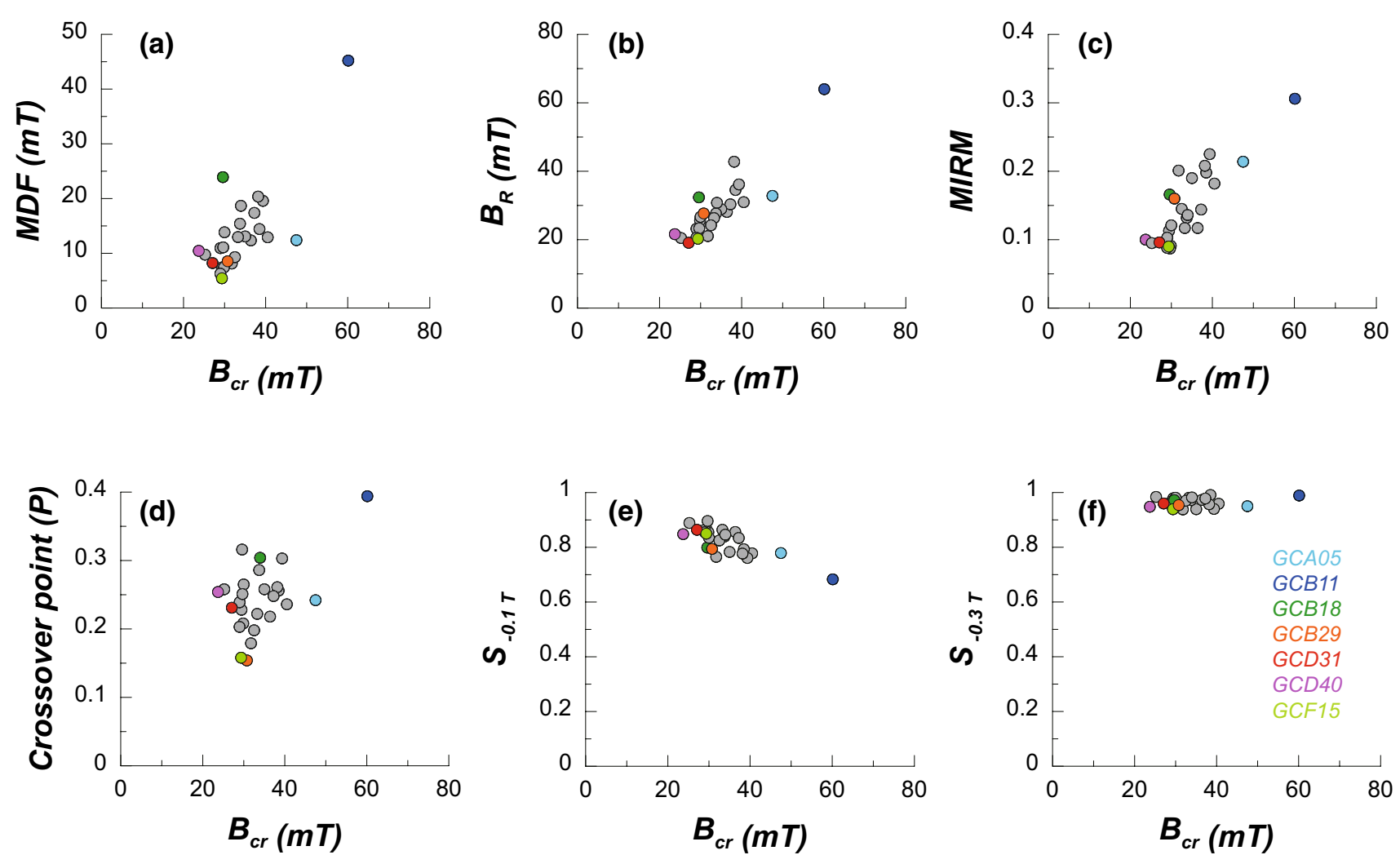

Fig. 8 Relation between various magnetic parameters including a median destructive field (MDF) and coercivity of remanence $\left(B_{\mathrm{cr}}\right)$, $\mathbf{b}$ crossover field $\left(B_{\mathrm{R}}\right)$ and $B_{\mathrm{cr}}$, $\mathbf{c}$ MIRM and $B_{\mathrm{cr}}, \mathbf{d}$ crossover point $(P)$ and $B_{\mathrm{cr}}, \mathbf{e} S_{-0.1 \mathrm{~T}}$ and $B_{\mathrm{cr}}$, and $\mathbf{f} S_{-0.3 \mathrm{~T}}$ and $B_{\mathrm{cr}}$

GCD40. Of course, distributions of dual coercivity components were not clearly separable as to blur overlapped coercivity intervals (Fig. 9a-e). Results from GCB11 (Fig. 9f) deserved special attention, because it showed the largest $B_{\text {cr }}$ values (Fig. 8). There was only a single component for GCB11 whose mean coercivity was peaked at $90.7 \mathrm{mT}$ (Fig. 9f).

What controls the magnetic coercivity spectra in the soil samples? Results from MaxUnMix are well-explained with two distributions of low coercivity phase (21.3-36.4 mT) and high coercivity phase (81.3-151.1 mT). Exceptional results for GCB11 can be regarded as a single coercivity distribution of entirely high-coercivity phase (Fig. 9f). However, a linkage between classical IRM-related parameters (Figs. 5, 6, 7 and 8) and IRM component analysis using MaxUnMix (Fig. 9) was far from being a simple linear relation. The bulk of the observations are consistent with the notion that both classical IRM-related parameters (i.e., $S$ ratios) and IRM component analysis using MaxUnMix are imperfect as a fine probe of granulometry. As the thermal demagnetization of composite IRM data yielded magnetite as the sole remanence carrier (Fig. 7a), it is possible that particle size distribution induced dual coercivity distribution in the soils samples. To this end, it is likely that the softer component was dominated by a lower coercivity component which is interpreted to be angular magnetite originated from exhaust emissions. On the other hand, the harder component was dominated by a high coercivity component that is fine-grained spherical magnetite resulted from fossil fuel combustion process.

\section{Conclusions}

Two dimensional map of magnetic susceptibility was constructed using the magnetic susceptibility data measured on 238 topsoil samples from six profiles in Daejeon, South Korea. High values of magnetic susceptibility were narrowly concentrated adjacent to the street. Magnetic susceptibility decreased away from the street. Presence of magnetic hotspots around the periphery with intensities of magnetic susceptibility near or over $50 \times 10^{-5}$ SI might represent the difference in topographic elevation and surface morphology, because magnetic particles were continuously accumulated in low elevations over time. The maximum unblocking temperatures of composite IRMs were $580{ }^{\circ} \mathrm{C}$, suggesting that 

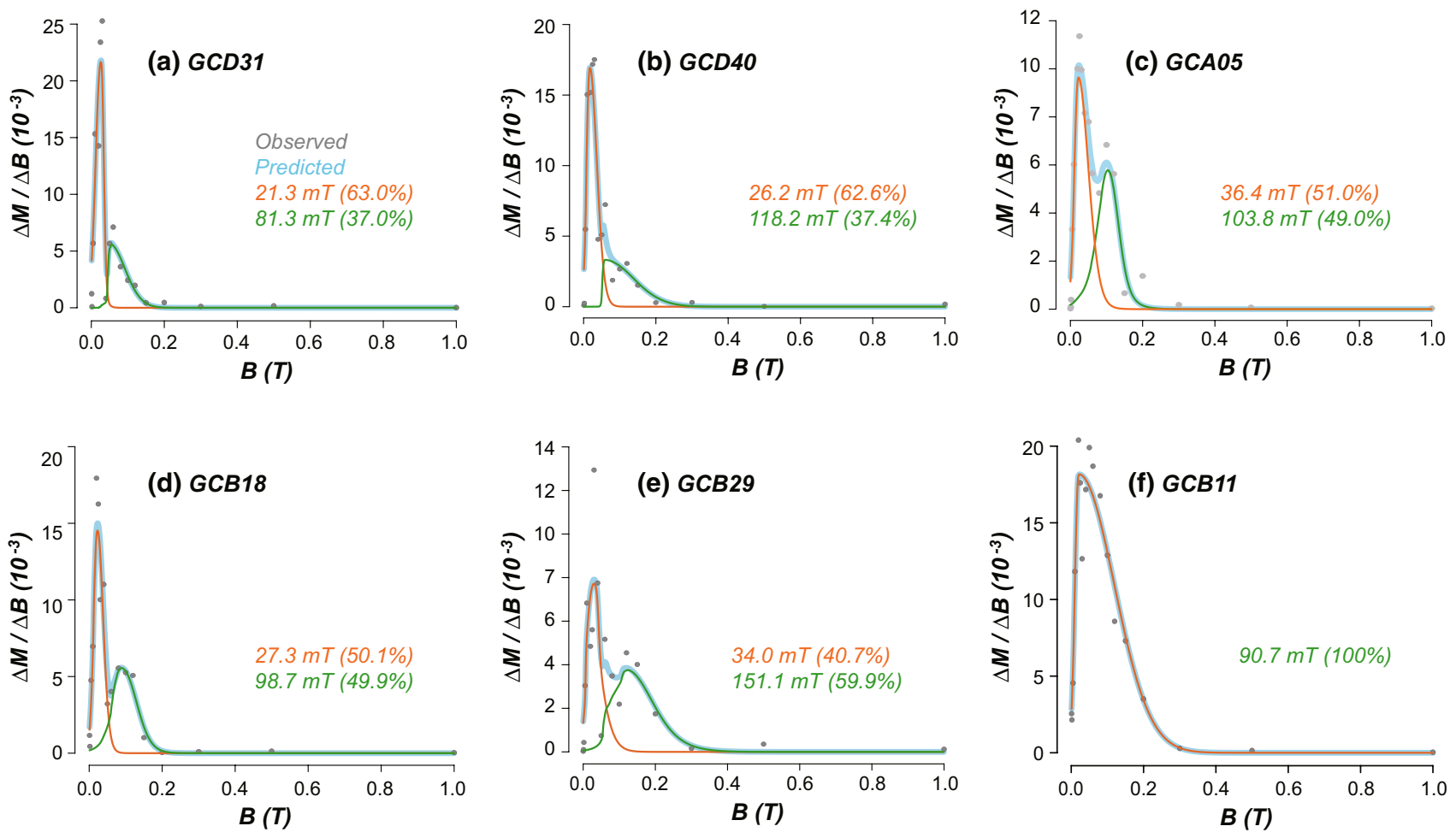

Fig. 9 Coercivity spectra of a GCD31, b GCD40, $\mathbf{c}$ GCA05, d GCB18, e GCB29, and f GCB11 determined from MaxUnMix software package (Maxbauer et al. 2016, 2017)

the magnetic mineralogy was dominated by magnetite. IRM component analysis showed dual coercivity peaks in most samples. It is likely that the softer component was dominated by coarse-grained angular magnetite originated from vehicle non-exhaust emissions. On the other hand, the harder component was dominated by fine-grained spherical magnetite resulted from exhaust emissions.

Acknowledgements The authors declare that they have no competing financial interests. All the data used for this study were tabulated in the Supplementary Excel file. We thank Nawrass Ameen and two anonymous referees for helpful reviews that greatly improved the paper. This work was supported by the National Research Foundation of Korea (NRF) grant funded by the Korea government (NRF2018R1A2B6001094) and by the Korea Foundation for the Advancement of Science \& Creativity (KOFAC), and funded by the Korean Government (MOE).

Open Access This article is licensed under a Creative Commons Attribution 4.0 International License, which permits use, sharing, adaptation, distribution and reproduction in any medium or format, as long as you give appropriate credit to the original author(s) and the source, provide a link to the Creative Commons licence, and indicate if changes were made. The images or other third party material in this article are included in the article's Creative Commons licence, unless indicated otherwise in a credit line to the material. If material is not included in the article's Creative Commons licence and your intended use is not permitted by statutory regulation or exceeds the permitted use, you will need to obtain permission directly from the copyright holder. To view a copy of this licence, visit http://creativecommons.org/licenses/by/4.0/.

\section{References}

Ayoubi S, Adman V (2019) Iron mineralogy and magnetic susceptibility of soils developed on various rocks in western Iran. Clays Clay Miner 67:217-227

Ayoubi S, Karimi R (2019) Pedotransfer functions for predicting heavy metals in natural soils using magnetic measures and soil properties. J Geochem Explor 197:212-219

Ayoubi S, Adman V, Yousefifard M (2019a) Efficacy of magnetic susceptibility technique to estimate metal concentration in some igneous rocks. Model Earth Syst Environ 5:1743-1750

Ayoubi S, Adman V, Yousefifar M (2019b) Use of magnetic susceptibility to assess metals concentration in soils developed on a range of parent materials. Ecotox Environ Safety 168:138-145

Baatar A, Ha R, Yu Y (2017) Do rainfalls wash out anthropogenic airborne magnetic particulates? Environ Sci Pollut Res 24:9713-9722

Blaha U, Appel E, Stanjek H (2008) Determination of anthropogenic boundary depth in industrially polluted soil and semi-quantification of heavy metal loads using magnetic susceptibility. Environ Pollut 156:278-289

Bloemendal J, King JW, Hall FR, Doh SJ (1992) Rock magnetism of Late Neogene and Pleistocene deep-sea sediments: relationship to sediment source, diagenetic processes and sediment lithology. J Geophys Res 97:4361-4375 
Bourliva A, Papadopoulou L, Aidona E (2016) Study of road dust magnetic phases as the main carrier of potentially harmful trace elements. Sci Total Environ 553:380-391

Bourliva A, Kantiranis N, Papadopoulou L, Aidona E, Christophoridis C, Kollias P, Evgenakis M, Fytianos L (2018) Seasonal and spatial variations of magnetic susceptibility and potentially toxic elements (PTEs) in road dusts of Thessaloniki city, Greece: A one-year monitoring period. Sci Total Environ 639:417-427

Boyko T, Scholger R, Stanjek H, MAGPROX Team (2004) Topsoil magnetic susceptibility mapping as a tool for pollution monitoring: repeatability of in situ measurements. J Appl Geophys 55:249-259

Bućko MS, Magiera T, Pesonen LJ, Janus B (2010) Magnetic, geochemical, and microstructural characteristics of road dust on roadsides with different traffic volumes - case study from Finland. Water Air Soil Pollut 209:295-306

Bućko MS, Magiera T, Johanson B, Petrovský E, Pesonen LJ (2011) Identification of magnetic particulates in road dust accumulated on roadside snow using magnetic, geochemical and micro-morphological analyses. Environ Pollut 159:1266-1276

Chaparro MAE, Bidegain JC, Sinito AM, Jurado SS, Gogorza CG (2004) Magnetic studies applied to different environments (soils and stream sediments) from a relatively polluted area in Buenos Aires Province, Argentina. Environ Geol 45:654-664

Dankoub Z, Ayoubi S, Khademi S, Lu SG (2012) Spatial distribution of magnetic properties and selected heavy metals in calcareous soils as affected by land use in the Isfahan region, Central Iran. Pedosphere 22:33-47

Dearing JA, Dann RJL, Hay K, Lees JA, Loveland PJ, Maher BA, O'Grady K (1996) Frequency-dependent susceptibility measurements of environmental materials. Geophys J Int 124:228-240

Dong C, Zhang W, Ma H, Feng H, Luc H, Dong Y, Yua L (2014) A magnetic record of heavy metal pollution in the Yangtze River subaqueous delta. Sci Total Environ 476-477:368-377

El-Hasan T (2008) The detection of roadside pollution of rapidly growing city in arid region using the magnetic proxies. Environ Geol $54: 23-29$

Evans ME, Heller F (2003) Environmental magnetism: principles and applications of enviromagnetics. Academic Press, San Diego, p 311

Gautam P, Blaha U, Appel E, Neupane G (2004) Environmental magnetic approach towards the quantification of pollution in Kathmandu urban area. Nepal Phys Chem Earth 29:973-984

Goodarzi F (2006) Characteristics and composition of fly ash from Canadian coal-fired power plants. Fuel 85:1418-1427

Grison H, Petrovský E, Stejskalova S, Kapička, (2015) Magnetic and geochemical characterization of Andosols developed on basalts in the Massif Central. France Geochem Geophys Geosyst 16(5):1348-1363

Ha R, Baatar A, Yu Y (2017) Identification of atmospheric transport and dispersion of Asian dust storms. Nat Hazards Earth Syst Sci 17:1425-1435

Hanesch M, Scholger R (2002) Mapping of heavy metal loadings in soils by means of magnetic susceptibility measurements. Environ Geol 42:857-870

Hanesch M, Scholger R, Rey D (2003) Mapping dust distribution around an industrial site by measuring magnetic parameters of tree leaves. Atmos Environ 37:5125-5133

Hanesch M, Rantitsch G, Hemetsberger S, Scholger R (2007) Lithological and pedological influences on the magnetic susceptibility of soil: Their consideration in magnetic pollution mapping. Sci Total Environ 382:351-363

Henkel O (1964) Remanenzverhalten und wechselwirkungen in hartmagnetischen teilchenkollektiven. Phys Status Solidi (b) 161:K41-K44 (in German)
Heslop D (2009) On the statistical analysis of the rock magnetic S-ratio. Geophys J Int 178:159-161

Hoffmann V, Knab M, Appel E (1999) Magnetic susceptibility mapping of roadside pollution. J Geochem Explor 66:313-326

Hwang J, Moon S (2018) Geochemical evidence for K-metasomatism related to uranium enrichment in Daejeon granitic rocks near the central Ogcheon Metamorphic Belt, Korea. Geosci J 22:1001-1013

Jelenska M, Hasso-Agopsowicz A, Kopcewicz B, Sukhorada A, Tyamina K, Kadzialko-Hofmoki M, Matviishina Z (2004) Magnetic properties of the profile of polluted and non-polluted soils: a case study from Ukraine. Geophys J Int 159:104-116

Jordanova N, Jordanova D, Henry B, Le Goff M, Dimov D, Tsacheva T (2006) Magnetism of cigarette ashes. J Mag Mag Mater 301:50-66

Jordanova N, Jordanova D, Tsacheva T (2008) Application of magnetometry for delineation of anthropogenic pollution in areas covered by various soil types. Geoderma 144:557-571

Jordanova D, Goddu SR, Kotsev T, Jordanova N (2013) Industrial contamination of alluvial soils near $\mathrm{Fe}-\mathrm{Pb}$ mining site revealed by 441 magnetic and geochemical studies. Geoderma 192:237-248

Karimi R, Ayoubi S, Jalalian A, Sheikh-Hosseini AR, Afyuni M (2011) Relationships between magnetic susceptibility and heavy metals in urban topsoils in the arid region of Isfahan, central Iran. J Appl Geophys 74:1-7

Karimi R, Haghnia GH, Ayoubi S, Safari T (2017) Impacts of geology and land use on magnetic susceptibility and selected heavy metals in surface soils of Mashhad plain, northeastern Iran. J Appl Geophys 128:127-134

Kim W, Doh SJ, Park YH (2007) Two-year magnetic monitoring in conjunction with geochemical and electron microscopic data of roadside dust in Seoul, Korea. Atmos Environ 41:7627-7641

Kim W, Doh SJ, Yu Y (2012) Asian dust storm as conveyance media of anthropogenic pollutants. Atmos Environ 49:41-50

King J, Banerjee SK, Marvin J, Özdemir Ö (1982) A comparison of different magnetic methods for determining the relative grain size of magnetite in natural materials: Some results from lake sediments. Earth Planet Sci Lett 59:404-419

Kruiver PP, Passier HF (2001) Coercivity analysis of magnetic phases in sapropel S1 related to variations in redox conditions, including an investigation of the S-ratio. Geochem Geophys Geosyst 2(12):1063. https://doi.org/10.1029/2001GC000181

Liu QS, Roberts AP, Torrent J, Horng CS, Larrasoaña JC (2007) What do the HIRM and S-ratio really measure in environmental magnetism? Geochem Geophys Geosyst 8:Q09011. https://doi. org/10.1029/2007GC001717

Liu QS, Roberts AP, Larrasoaña JC, Banerjee SK, Guyodo Y, Tauxe L, Oldfield F (2012) Environmental magnetism: principles and applications. Rev Geophys 50:1-50

Lowrie W (1990) Identification of ferromagnetic minerals in a rock by coercivity and unblocking temperature properties. Geophys Res Lett 17:159-162

Lu SG, Bai SQ (2006) Study on the correlation of magnetic properties and heavy metals content in urban soils of Hangzhou City, China. J Appl Geophys 60:1-12

Lu SG, Bai SQ, Xue QF (2007) Magnetic properties as indicators of heavy metal pollution in urban topsoils: a case study from the city of Luoyang, China. Geophys J Int 171:568-580

Lu SG, Wang HY, Guo JL (2011) Magnetic enhancement of urban roadside soils as a proxy. Environ Earth Sci 64:359-371

Ma M, Hu S, Wang L, Appel E (2016) The distribution process of traffic contamination on roadside surface and the influence of meteorological conditions revealed by magnetic monitoring. Environ Monitor Assess 188:650. https://doi.org/10.1007/s1066 1-016-5661-0 
Magiera T, Jablońska M, Strzyszcz Z, Rachwal M (2011) Morphological and mineralogical forms of technogenic magnetic particles in industrial dusts. Atmos Environ 45:4281-4290

Magiera T, Goluchowska B, Jablońska M (2013) Technogenicmagnetic particles in alkaline dusts from power and cement plants. Water Air Soil Pollut 224:1389-1405

Maher BA, Moore C, Matzka J (2008) Spatial variation in vehicle derived metal pollution identified by magnetic and elemental analysis of roadside tree leaves. Atmos Environ 42:364-373

Matzka J, Maher BA (1999) Magnetic biomonitoring of roadside tree leaves: identification of spatial and temporal variations in vehiclederived particulates. Atmos Environ 33:4565-4569

Maxbauer DP, Feinberg JM, Fox DL (2016) MaxUnMix: A web application for unmixing magnetic coercivity distributions. Comp Geosci 95:140-145

Maxbauer DP, Feinberg JM, Fox DL, Nater E (2017) Response of pedogenic magnetite to changing vegetation in soils developed under uniform climate, topography, and parent material. Sci Reports 7:17575. https://doi.org/10.1038/s41598-017-17722-2

Mayo PI, Erkkila RM, Bradbury A, Chantrell RW (1990) Interaction effects in longitudinally oriented and non-oriented barium hexaferrite tapes. IEEE Trans Mag 26(5):1894-1896

Mayo PI, O'Grady K, Chantrell RW, Cambridge JA, Sanders IL, Yogi T, Howard JK (1991a) Magnetic measurement of interaction effects in CoNiCr and CoPtCr thin film media. J Mag Mag Mater 95(1):109-117

Mayo PI, O'Grady K, Kelly PE, Cambridge J, Sanders IL, Yogi T, Chantrell RW (1991b) A magnetic evaluation of interaction and noise characteristics of $\mathrm{CoNiCr}$ thin films. J Appl Phys 69(8):4733-4735

Muxworthy AR, Matzka J, Petersen N (2001) Comparison of magnetic parameters of urban atmospheric particulate matter with pollution and meteorological data. Atmos Environ 35:4379-4386

Nikolaeva O, Rozanova M, Karpukhin M (2017) Distribution of trafficrelated contaminants in urban topsoils across a highway in Moscow. J Soils Sediments 17:1045-1053

Ojha G, Appel E, Wawer M, Magiera T, Hu S (2016) Toward a costefficient method for monitoring of traffic-derived pollutants with quartz sand boxes. Water Air Soil Pollut 227:173. https://doi. org/10.1007/s11270-016-2858-3

Petrovský E, Hejda P, Zelinka T, Kropáček V, Šubrt J (1993) Experimental determination of magnetic interaction within a system of synthetic hematite particles. Phys Earth Planet Inter 76(1-2):123-130

Petrovský E, Kapička A, Jordanova N, Knab M, Hoffmann V (2000) Low-field magnetic susceptibility: a proxy method of estimating increased pollution of different environmental systems. Environ Geol 39:312-318

Pierwola J, Szuszkiewicz M, Cabala J, Jochymczyk K, Żogała B, Magiera T (2020) Integrated geophysical and geochemical methods applied for recognition of acid waste drainage (AWD) from $\mathrm{Zn}-\mathrm{Pb}$ post-flotation tailing pile (Olkusz, southern Poland). Environ Sci Pollut Res 27:16731-16744

Prajapati SK, Pandey SK, Tripathi BD (2006) Monitoring of vehicles derived particulates using magnetic properties of leaves. Environ Monitor Assess 120:169-175

Salomé AL, Meynadier L (2004) Magnetic properties of rivers sands and rocks from Martinique Island: tracers of weathering? Phys Chem Earth 29(3-4):933-945

Schmidt A, Yarnold R, Hill M, Ashmore M (2005) Magnetic susceptibility as proxy for heavy metal pollution: a site study. J Geochem Explor 85:109-117
Shilton VF, Booth CA, Smith JP, Giess P, Mitchell DJ, Williams CD (2005) Magnetic properties of urban street dust and their relationship with organic matter content in the West Midlands, UK. Atmos Environ 39:3651-3659

Speliotis DE, Lynch W (1991) Magnetic interaction in particulate and thin-film recording media. J Appl Phys 69(8):4496-4498

Spiteri C, Kalinski V, Rosler W, Hoffmann V, Appel E, MAGPROX team (2005) Magnetic screening of a pollution hotspot in the Lausitz area, Eastern Germany: correlation analysis between magnetic proxies and heavy metal contamination in soils. Environ Geol 49:1-9

Stober JC, Thompson R (1979) An investigation into the source of magnetic minerals in some Finnish lake sediments. Earth Planet Sci Lett 45:464-474

Tolonen K, Oldfield F (1986) The record of magnetic-mineral and heavy metal deposition at Regent Street Bog, Fredricton, New Brunswick, Canada. Phys Earth Planet Inter 42:57-66

Torrent J, Liu Q, Barrón V (2010) Magnetic susceptibility changes in relation to pedogenesis in a Xeralf chronosequence in northwestern Spain. Eur J Soil Sci 61:161-173

Wawer M, Magiera T, Ojha G, Appel E, Kusza G, Hu S, Basavaiah B (2015) Traffic-related pollutants in roadside soils of different countries in Europe and Asia. Water Air Soil Pollut. https://doi. org/10.1007/s11270-015-2483-6

Werkenthin M, Kluge B, Wessolek G (2014) Metals in European roadside soils and soil solution—a review. Environ Pollut 189:98-110

Wohlfarth EP (1958) Relations between different modes of the acquisition of the remanent magnetization of ferromagnetic particles. J Appl Phys 29:595-596

Yamazaki T, Abdeldayem AL, Ikehara L (2003) Rock-magnetic changes with reduction diagenesis in Japan Sea sediments and preservation of geomagnetic secular variation in inclination. Earth Planets Space 55:327-340

Yan HT, Hu SY, Blaha U, Rösler W, Duan XM, Appel E (2011) Paddy soil - A suitable target for monitoring heavy metal pollution by magnetic proxies. J Appl Geophys 75:211-219

Yang T, Liu Q, Chan L, Liu Z (2007) Magnetic signature of heavy metals pollution of sediments: case study from the East Lake in Wuhan, China. Environ Geol 52:1639-1650

Yang T, Liu Q, Zeng Q, Chan L (2009) Environmental magnetic responses of urbanization processes: evidence from lake sediments in East Lake, Wuhan. China Geophys J Int 179(2):873-886

Yang T, Liu Q, Li H, Zeng Q, Chan L (2010) Anthropogenic magnetic particles and heavy metals in the road dust: magnetic identification and its implications. Atmos Environ 44:1175-1185

Zechmeister HG, Hohenwallner D, Riss A, Hanus-Illnar A (2005) Estimation of element deposition derived from road traffic sources by using mosses. Environ Pollut 138:238-249

Zhang C, Qiao Q, Piper JDA, Huang B (2011) Assessment of heavy metal pollution from a Fe-smelting plant in urban river sediments using environmental magnetic and geochemical methods. Environ Pollut 159:3057-3070

Zhu Z, Li Z, Bi X, Han Z, Yu G (2013) Response of magnetic properties to heavy metal pollution in dust from three industrial cities in China. J Hazard Mater 246-247:189-198

Publisher's Note Springer Nature remains neutral with regard to jurisdictional claims in published maps and institutional affiliations. 